\title{
Effect of Alkali Metal Ions on Nucleophilic Substitution Reactions of 4-Nitrophenyl X-Substituted Benzoates with Alkali Metal Ethoxides in Anhydrous Ethanol
}

\author{
Jin-A Seo, Song-I Kim, Yeon-Ju Hong, ${ }^{\dagger}$ and Ik-Hwan Um* \\ Department of Chemistry and Nano Science, Ewha Womans University, Seoul 120-750, Korea. *E-mail: ihum@ewha.ac.kr \\ ${ }^{\dagger}$ Amorepacific Corporation R\&D Center, Yongin 446-729, Korea \\ Received October 13, 2009, Accepted December 10, 2009
}

\begin{abstract}
Pseudo-first-order rate constants $\left(k_{\mathrm{obsd}}\right)$ have been measured spectrophotometrically for nucleophilic substitution reactions of 4-nitrophenyl benzoate (5a), 4-nitrophenyl 4-methoxybenzoate (5b), and 4-nitrophenyl 4-hydroxybenzoate (5c) with alkali metal ethoxides, $\mathrm{EtO}^{\circ} \mathrm{M}^{+}\left(\mathrm{M}^{+}=\mathrm{Li}^{+}, \mathrm{Na}^{+}\right.$and $\left.\mathrm{K}^{+}\right)$in anhydrous ethanol $(\mathrm{EtOH})$ at $25.0 \pm 0.1{ }^{\circ} \mathrm{C}$. The plots of $k_{\text {obsd }} v s$. [EtO $\mathrm{M}^{+}$] exhibit upward curvatures in all cases, indicating that $\mathrm{M}^{+}$ions catalyze the reactions and ionpaired $\mathrm{EtO}^{-} \mathrm{M}^{+}$species are more reactive than dissociated $\mathrm{EtO}^{-}$. Second-order rate constants for reactions with dissociated $\mathrm{EtO}^{-}$and ion-paired $\mathrm{EtO}^{-} \mathrm{M}^{+}$(i.e., $k_{\mathrm{EtO}^{-}}$and $k_{\mathrm{EtO}^{-} \mathrm{M}^{+}}$, respectively) have been calculated from ion-pair treatment for the reactions of $\mathbf{5 a}$ and $\mathbf{5 b}$. However, such ion-pair treatment has failed to determine $k_{\mathrm{EtO}}$ and $k_{\mathrm{EtO}} \mathrm{M}^{+}$values for the reactions of $\mathbf{5 c}$. It has been concluded that reactions of $\mathbf{5 a}$ and $\mathbf{5 b}$ are catalyzed by one metal ion, which increases electrophilicity of the reaction center through coordination on the carbonyl oxygen. In contrast, reactions of $5 \mathbf{c}$ have been suggested to involve two metal ions, i.e., the one coordinated on the carbonyl oxygen increases the electrophilicity of the reaction center while the other one associated on the phenoxy oxygen decreases the charge repulsion between the anionic reagents (i.e., $\mathrm{EtO}^{-}$and deprotonated $\mathbf{5 c}$ ). It has been found that the rate equation derived from the mechanism involving two metal ions fits nicely to the kinetic results obtained for the reactions of $\mathbf{5 c}$.
\end{abstract}

Key Words: Metal ion catalysis, Crown ether, Ion-pair, Electrophilicity, Nucleofugality

\section{Introduction}

Effects of metal ions on nucleophilic substitution reactions have been intensively studied due to their importance in chemistry as well as biological processes. ${ }^{1-10}$ However, most studies have been focused on catalytic effects shown by di- or trivalent metal ions (e.g., $\mathrm{Mg}^{2+}, \mathrm{Ca}^{2+}, \mathrm{Mn}^{2+}, \mathrm{Cu}^{2+}, \mathrm{Zn}^{2+}, \mathrm{La}^{3+}, \mathrm{Eu}^{3+}, \mathrm{Co}^{3+}$, etc.). ${ }^{1-4}$ The effect of alkali metal ions on nucleophilic substitution reactions has been much less investigated although alkali metal ions are ubiquitous in biological systems. Buncel et al. performed a systematic study on nucleophilic substitution reactions of 4-nitrophenyl diphenylphosphinate (1) with $\mathrm{EtO}^{-} \mathrm{M}^{+}$ $\left(\mathrm{M}^{+}=\mathrm{Li}^{+}, \mathrm{Na}^{+}, \mathrm{K}^{+}\right)$to investigate the role of alkali metal ions. ${ }^{5}$ They found that alkali metal ions catalyze the reactions of $\mathbf{1}$ as Lewis acid catalysts and the catalytic effect decreases as the size of $\mathrm{M}^{+}$ions increases (i.e., $\mathrm{Li}^{+}>\mathrm{Na}^{+}>\mathrm{K}^{+}$).

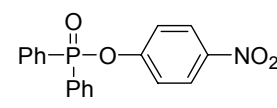

1

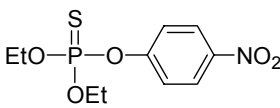

3

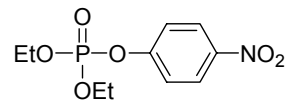

2

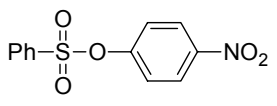

4
We have recently shown that alkali metal ions behave as Lewis acid catalysts in alkaline ethanolysis of 4-nitrophenyl diethylphosphate (2, paraoxon) and the catalytic effect increases as the size of $\mathrm{M}^{+}$ion decreases. ${ }^{9}$ In contrast, in alkaline ethanolysis of 4-nitophenyl diethylphosphorothioate (3, parathion), the thio analogues of $\mathbf{2}$, we found that $\mathrm{K}^{+}$and $\mathrm{Na}^{+}$exhibit catalytic effect while $\mathrm{Li}^{+}$ion behaves as an inhibitor. ${ }^{9}$ A similar result has been reported by Pregel et al. for reactions of 4-nitrophenyl benzenesulfonate (4) with $\mathrm{EtO}^{-} \mathrm{M}^{+}$, i.e., catalysis by $\mathrm{K}^{+}$and $\mathrm{Na}^{+}$ ions and inhibition by $\mathrm{Li}^{+}$ion, ${ }^{8}$ indicating that the role of $\mathrm{M}^{+}$ ions depends on the nature of the electrophilic centers (e.g., $\mathrm{P}=\mathrm{O}, \mathrm{P}=\mathrm{S}, \mathrm{SO}_{2}$ ).

We have extended our study to alkaline ethanolysis of 4-nitrophenyl X-substituted benzoates (5a-c) as shown in Scheme 1 to investigate the effect of $\mathrm{M}^{+}$ions on reactions of the $\mathrm{C}=\mathrm{O}$ centered electrophile. We have found: (1) Ion-paired $\mathrm{EtO}^{-}$ $\mathrm{M}^{+}$species are more reactive than dissociated $\mathrm{EtO}^{-}$ion and $\mathrm{M}^{+}$ ions catalyze the reactions of 5a-c. (2) One metal ion is involved in the reactions of $\mathbf{5} \mathbf{a}$ and $\mathbf{5} \mathbf{b}$, while two metal ions are involved in the corresponding reactions of $\mathbf{5 c}$. The roles of metal ions (e.g., increase in electrophilicity/nucleofugality) are discussed together with plausible transition-state structures.

\section{Results and Discussion}

The kinetic study was performed spectrophotometrically under pseudo-first-order conditions with a large excess of

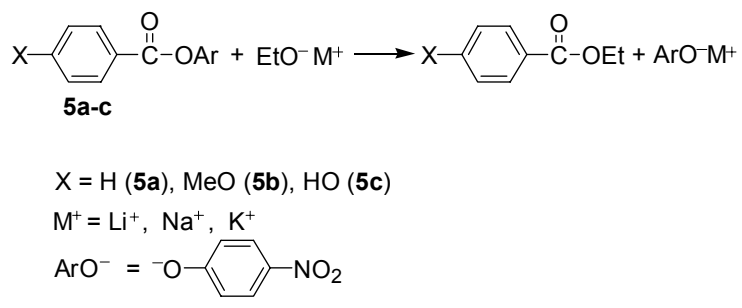

Scheme 1 
$\mathrm{EtO}^{-} \mathrm{M}^{+}$. All reactions in the current study obeyed pseudo-firstorder kinetics. Pseudo-first-order rate constants $\left(k_{\text {obsd }}\right)$ were obtained from the plots of $\ln \left(A_{\infty}-A_{t}\right) v s$. $t$. It is estimated from replicate runs that the uncertainty in the $k_{\text {obsd }}$ values is less than $\pm 3 \%$. The $k_{\text {obsd }}$ values and kinetic conditions for the reactions of 5a-c with EtO $\mathrm{M}^{+}$are summarized in Tables S1-S4 in the Supporting Information. The second-order rate constants $\left(k_{\mathrm{EtO}}-\right.$ and $\left.k_{\mathrm{EtO}^{-}} \mathrm{M}^{+}\right)$for the reactions of $\mathbf{5 a}$ and $\mathbf{5 b}$ were determined from the ion-pairing treatment of the kinetic data and summarized in Table 1, while the parameters determined from curve fittings for the corresponding reactions of $\mathbf{5 c}$ are shown in Table 2.

Reactions of Neutral Substrates 5a and 5b. As shown in Figure 1A, the reactivity of EtO $\mathrm{Li}^{+}$toward $\mathbf{5 a}$ is similar to those of $\mathrm{EtO}^{-} \mathrm{Na}^{+}$and $\mathrm{EtO}^{-} \mathrm{K}^{+}$in a low concentration region (e.g., $\left.\left[\mathrm{EtO}^{-} \mathrm{M}^{+}\right]<5 \mathrm{mM}\right)$. However, $\mathrm{EtO}^{-} \mathrm{Li}^{+}$becomes less reactive than $\mathrm{EtO}^{-} \mathrm{Na}^{+}$and $\mathrm{EtO}^{+}$as the concentration increases further. A similar result is shown in Figure 1B for the corresponding

(A)

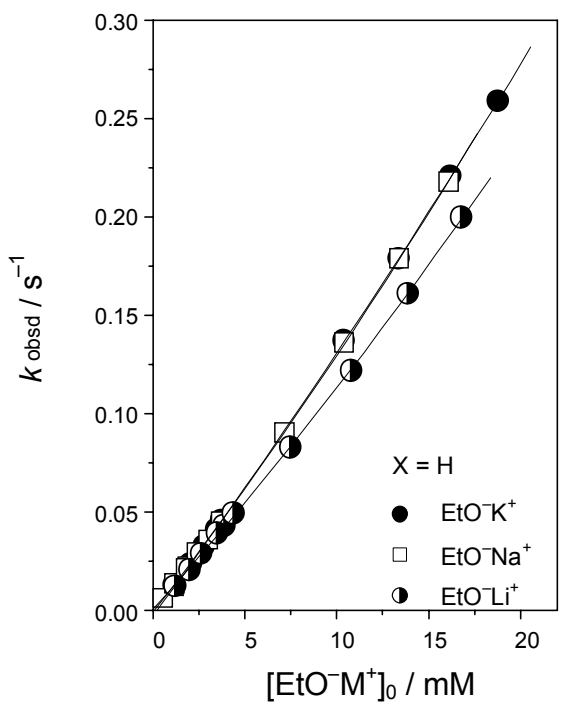

(B)

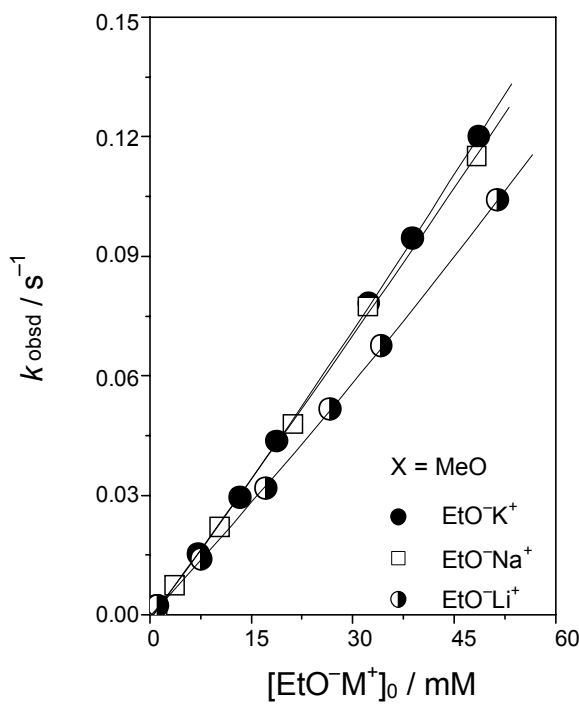

Figure 1. Plots of $k_{\mathrm{obsd}} v s$. [EtO $\left.\mathrm{M}^{+}\right]$for reactions of 4-nitrophenyl benzoate $(\mathbf{5} \mathbf{a}, \mathrm{A})$ and 4-nitrophenyl 4-methoxybenzoate $(\mathbf{5} \mathbf{b}, \mathrm{B})$ with $\mathrm{EtO}^{+}(\bullet), \mathrm{EtO} \mathrm{Na}^{+}(\square)$, and $\mathrm{EtO}^{-} \mathrm{Li}^{+}(\boldsymbol{\bullet})$ in anhydrous $\mathrm{EtOH}$ at 25.0 $\pm 0.1{ }^{\circ} \mathrm{C}$. The curved lines were drawn from eq (2). reactions of $\mathbf{5 b}$, although $\mathbf{5 b}$ is much less reactive than $\mathbf{5 a}$ due to the presence of an electron donating substituent $(\mathrm{MeO})$ on the benzoyl moiety.

A careful examination of Figures $1 \mathrm{~A}$ and $1 \mathrm{~B}$ reveals that plots of $k_{\text {obsd }} v s$. [EtO $\mathrm{M}^{+}$] are not linear but exhibit a slightly upward curvature in all cases. Such an upward curvature has been reported for alkaline ethanolyses of $\mathrm{P}=\mathrm{O}, \mathrm{P}=\mathrm{S}, \mathrm{SO}_{2}$ and other $\mathrm{C}=\mathrm{O}$ centered electrophiles, in which $\mathrm{M}^{+}$ions behave as Lewis acid catalysts and ion-paired $\mathrm{EtO}^{-} \mathrm{M}^{+}$species are more reactive than dissociated $\mathrm{EtO}^{-}$ion. ${ }^{5-10}$ Thus, one can suggest that $\mathrm{M}^{+}$ions behave as Lewis acid catalysts in the current reactions of $\mathbf{5 a}$ and $\mathbf{5 b}$.

It has been reported that $\mathrm{EtO}^{-} \mathrm{M}^{+}$may exist as dimers or other aggregates in the high concentration $\left(e . g .,\left[\mathrm{EtO}^{-} \mathrm{M}^{+}\right]>0.1 \mathrm{M}\right){ }^{11}$ However, in concentration below $0.1 \mathrm{M}$ as in the current study, $\mathrm{EtO}^{-} \mathrm{M}^{+}$has been suggested to exist mainly as dissociated and ion-paired species. ${ }^{11}$ Since both dissociated $\mathrm{EtO}^{-}$and ion-paired $\mathrm{EtO}^{-} \mathrm{M}^{+}$can react with the substrates as shown in Scheme 2, one can derive a rate equation in eq $(1)$, in which $k_{\mathrm{EtO}^{-}}$and $k_{\mathrm{EtO}^{-} \mathrm{M}^{+}}$ represent the second-order rate constants for the reaction with dissociated $\mathrm{EtO}^{-}$and ion-paired $\mathrm{EtO}^{-} \mathrm{M}^{+}$, respectively. ${ }^{5}$

Since the association constant, $K_{\mathrm{as}}=\left[\mathrm{EtO}^{-} \mathrm{M}^{+}\right] /\left[\mathrm{EtO}^{-}\right]\left[\mathrm{M}^{+}\right]$ and $\left[\mathrm{EtO}^{-}\right]=\left[\mathrm{M}^{+}\right]$at equilibrium, eq (2) becomes eq (3). The concentration of $\mathrm{EtO}^{-}$at equilibrium can be calculated from the $K_{\text {as }}$ value reported previously ${ }^{12}$ and the initial EtO $\mathrm{M}^{+}$concentration.

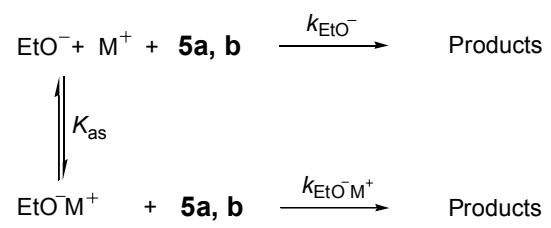

Scheme 2

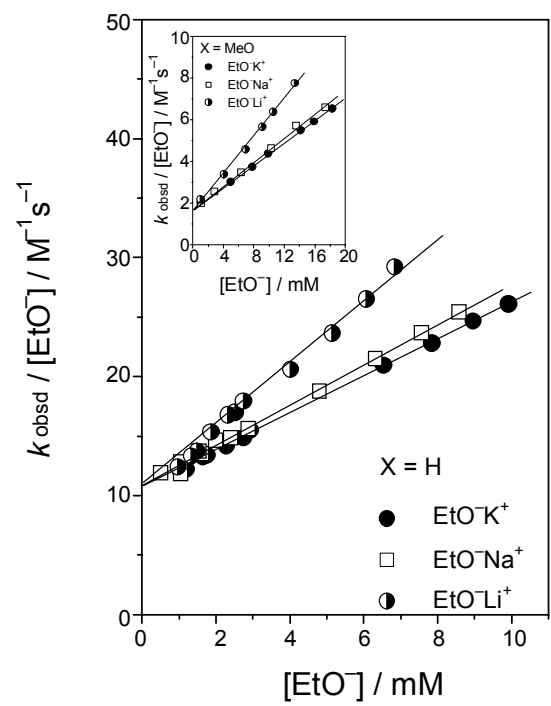

Figure 2. Plots illustrating dissection of $k_{\text {obsd }}$ into second-order rate constants $k_{\mathrm{EtO}^{-}}$and $k_{\mathrm{EtO}^{-} \mathrm{M}^{+}}$for the reactions of 4-nitrophenyl benzoate (5a) and 4-nitrophenyl 4-methoxybenzoate (5b, inset) with EtO $\mathrm{M}^{+}$in anhydrous $\mathrm{EtOH}$ at $25.0 \pm 0.1^{\circ} \mathrm{C}$. 
Table 1. Summary of Second-Order Rate Constants from Ion-Pairing Treatment of Kinetic Data for Reactions of 4-Nitrophenyl Benzoate (5a) and 4-Nitrophenyl 4-Methoxybenzoate (5b) with $\mathrm{EtO}^{-} \mathrm{M}^{+}$in Anhydrous EtOH at $25.0 \pm 0.1^{\circ} \mathrm{C}$.

\begin{tabular}{|c|c|c|c|c|}
\hline \multirow{2}{*}{$\mathrm{EtO}^{-} \mathrm{M}^{+}$} & \multicolumn{2}{|c|}{$\mathrm{X}=\mathrm{H}(\mathbf{5 a})$} & \multicolumn{2}{|c|}{$\mathrm{X}=\mathrm{MeO}(\mathbf{5} \mathbf{b})$} \\
\hline & $k_{\mathrm{EtO}^{-} \mathrm{M}^{+}} / \mathrm{M}^{-1} \mathrm{~s}^{-1}$ & $k_{\mathrm{EtO}}-/ \mathrm{M}^{-1} \mathrm{~s}^{-1}$ & $k_{\mathrm{EtO}^{-} \mathrm{M}^{+}} / \mathrm{M}^{-1} \mathrm{~s}^{-1}$ & $k_{\mathrm{EtO}^{-}} / \mathrm{M}^{-1} \mathrm{~s}^{-1}$ \\
\hline $\mathrm{EtO}^{-} \mathrm{Li}^{+}$ & $13.1 \pm 0.3$ & $9.83 \pm 0.22$ & $2.13 \pm 0.06$ & $1.59 \pm 0.11$ \\
\hline $\mathrm{EtO} \mathrm{Na}^{+}$ & $16.6 \pm 0.3$ & $10.8 \pm 0.1$ & $2.80 \pm 0.06$ & $1.70 \pm 0.06$ \\
\hline $\mathrm{EtO}^{-} \mathrm{K}^{+}$ & $17.5 \pm 0.2$ & $10.5 \pm 0.1$ & $2.92 \pm 0.02$ & $1.73 \pm 0.03$ \\
\hline
\end{tabular}

$$
\begin{aligned}
& \text { Rate }=k_{\mathrm{EtO}^{-}}\left[\mathrm{EtO}^{-}\right][5]+k_{\mathrm{EtO}^{-} \mathrm{M}^{+}}\left[\mathrm{EtO}^{-} \mathrm{M}^{+}\right][5] \\
& k_{\text {obsd }}=k_{\mathrm{EtO}^{-}}\left[\mathrm{EtO}^{-}\right]+k_{\mathrm{EtO}^{-} \mathrm{M}^{+}}\left[\mathrm{EtO}^{-} \mathrm{M}^{+}\right] \\
& k_{\text {obsd }}\left[\left[\mathrm{EtO}^{-}\right]=k_{\mathrm{EtO}^{-}}+K_{\text {as }} k_{\mathrm{EtO}^{-} \mathrm{M}^{+}}\left[\mathrm{EtO}^{-}\right]\right.
\end{aligned}
$$

If the current reactions proceed as proposed in Scheme 2, one might expect that the plots of $k_{\text {obsd }} /\left[\mathrm{EtO}^{-}\right] v s .\left[\mathrm{EtO}^{-}\right]$are linear and pass through a common intercept. In fact, as shown in Figure 2 (and inset), all plots are linear and pass through a common intercept regardless of the nature of $\mathrm{M}^{+}$ions, indicating that both dissociated $\mathrm{EtO}^{-}$and ion-paired $\mathrm{EtO}^{-} \mathrm{M}^{+}$react with substrates $\mathbf{5 a}$ and $\mathbf{5 b}$ as proposed in Scheme 2. Thus, one can determine $k_{\mathrm{EtO}}{ }^{-}$and $K_{\text {as }} k_{\mathrm{EtO}^{-} \mathrm{M}^{+}}$values from the intercept and slope of the linear plots, respectively. Since the $K_{\mathrm{as}}$ values of $\mathrm{EtO}^{-} \mathrm{Li}^{+}, \mathrm{EtO}^{-}$ $\mathrm{Na}^{+}$and $\mathrm{EtO}^{-} \mathrm{K}^{+}$have been reported to be 212,102 , and $90 \mathrm{M}^{-1}$ for this series, ${ }^{12}$ the $k_{\mathrm{EtO}^{-}} \mathrm{M}^{+}$value can be calculated from the slope of the linear plots in Figure 2 . The $k_{\mathrm{EtO}^{-}}$and $k_{\mathrm{EtO}^{-} \mathrm{M}^{+}}$values determined in this way are summarized in Table 1.

Table 1 shows that $k_{\mathrm{EtO}^{-} \mathrm{M}^{+}}$increases as the size of $\mathrm{M}^{+}$ion increases, i.e., the $k_{\mathrm{EtO}^{-} \mathrm{M}^{+}}$values for the reactions of $\mathbf{5 a}$ with $\mathrm{EtO}^{-} \mathrm{Li}^{+}, \mathrm{EtO}^{-} \mathrm{Na}^{+}$and $\mathrm{EtO}^{-} \mathrm{K}^{+}$are $13.1 \pm 0.3,16.6 \pm 0.3$ and $17.5 \pm 0.2 \mathrm{M}^{-1} \mathrm{~s}^{-1}$, respectively. In contrast, $k_{\mathrm{EtO}^{-}}$is almost identical within an experimental error $\left(k_{\mathrm{EtO}}=10.3 \pm 0.5 \mathrm{M}^{-1} \mathrm{~s}^{-1}\right)$. Similar results are obtained for the corresponding reactions of $5 \mathbf{b}$, although $5 \mathbf{b}$ resulted in $c a .6$ times smaller $k_{\mathrm{EtO}}-$ and $k_{\mathrm{EtO}^{-} \mathrm{M}^{+}}$ values than $\mathbf{5 a}$ due to the electron-donating substituent, $\mathrm{MeO}$ on the benzoyl moiety. It is also noted that $k_{\mathrm{EtO}^{-} \mathrm{M}^{+}}$is larger than $k_{\mathrm{EtO}}-$ for the reactions of $\mathbf{5 a}$ and $\mathbf{5 b}$, indicating that the ionpaired $\mathrm{EtO}^{-} \mathrm{M}^{+}$species are more reactive than dissociated $\mathrm{EtO}^{-}$ and alkali metal ions catalyze the reactions of $\mathbf{5} \mathbf{a}$ and $\mathbf{5} \mathbf{b}$.

The catalytic effect of $\mathrm{M}^{+}$ions has been reported to decrease in the order $\mathrm{Li}^{+}>\mathrm{Na}^{+}>\mathrm{K}^{+}$for alkaline ethanolysis of 4-nitrophenyl diphenylphosphinate (1) $)^{5}$ and paraoxon $(\mathbf{2})^{9}$ while $\mathrm{K}^{+}>$ $\mathrm{Na}^{+}>\mathrm{Li}^{+}$for reactions of parathion (3) and 4-nitrophenyl benzenesulfonate (4). ${ }^{8}$ Table 1 shows that the order of catalytic effects increases as the size of $\mathrm{M}^{+}$ion increases, which is opposite to that reported previously for the corresponding reactions of $\mathrm{P}=\mathrm{O}$ centered electrophiles, ${ }^{5,9}$ but the same as that reported for the reactions of $\mathrm{P}=\mathrm{S}$ and $\mathrm{SO}_{2}$ centered electrophiles. ${ }^{8}$ Thus, the current study supports the argument that the role of metalions is dependent on the nature of the electrophilic center.

One might suggest that $\mathrm{M}^{+}$ions in this study exhibit catalytic effect by enhancing nucleofugality through coordination on the $\mathrm{O}$ atom of the leaving 4-nitrophenoxide and/or by increasing electrophilicity of the reaction center through complexing with the $\mathrm{O}$ atom of the $\mathrm{C}=\mathrm{O}$ bond as modeled by I and II. However, the effect of enhanced nucleofugality would be significant only for reactions in which leaving-group departure occurs in the rate-determining step (RDS). Alkaline ethanolysis of aryl benzoates has been reported to proceed through a stepwise mechanism, in which expulsion of the leaving group occurs after RDS. ${ }^{13}$ Thus, enhanced nucleofugality through coordination of $\mathrm{M}^{+}$on the $\mathrm{O}$ atom of the leaving aryloxide (i.e., I) would be little responsible for the catalytic effect shown by $\mathrm{M}^{+}$ions in the reactions of $\mathbf{5 a}$ and $\mathbf{5} \mathbf{b}$. Instead, enhanced electrophilicity through complexation of $\mathrm{M}^{+}$with the $\mathrm{O}$ atom of the carbonyl group (i.e., II) is considered to be mainly responsible for the metal ion catalysis.
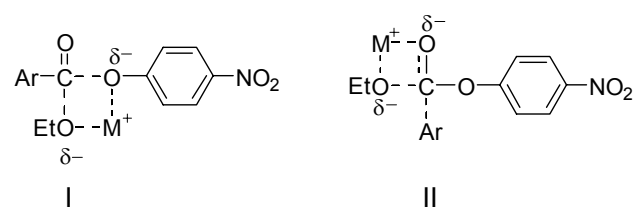

One might expect that the interaction between $\mathrm{M}^{+}$and the $\mathrm{O}$ atom of the carbonyl group becomes stronger as charge polarization of the $\mathrm{C}=\mathrm{O}$ bond increases. In fact, we have shown that the effect of polarization of electrophilic center $(e . g$., the $\mathrm{C}=\mathrm{O}$ bond in III and IV) on reactivity is significant for nucleophilic substitution reactions of aryl benzoates and related esters with amines as well as with anionic nucleophiles such as $\mathrm{OH}^{-}, \mathrm{CN}^{-}$, and $\mathrm{N}_{3}{ }^{-}$ions. ${ }^{14,15}$ Thus, reactions of $\mathbf{5 c}$, which has a strong electron-donating substituent on the benzoyl moiety, has been performed to get further information on the role of $\mathrm{M}^{+}$ion. The kinetic results will be discussed in the following section.

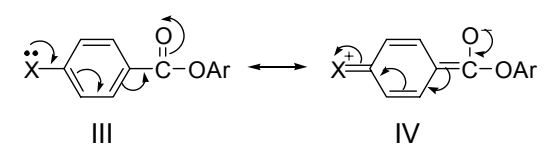

Reactions of Anionic Substrate $\mathbf{5 c}^{-}$. As shown in Figure 3, the plots of $k_{\text {obsd }} v s$. [EtO $\mathrm{M}^{+}$] for reactions of $\mathbf{5 c}$ curve upward as the concentration of $\mathrm{EtO}^{-} \mathrm{M}^{+}$increases. Besides, the reactivity of EtO $\mathrm{M}^{+}$toward $\mathbf{5 c}$ is highly dependent on the nature of $\mathrm{M}^{+}$ions, i.e., the reactivity of $\mathrm{EtO}^{-} \mathrm{M}^{+}$decreases as the size of $\mathrm{M}^{+}$ions decreases. It is also noted that $\mathrm{EtO}^{-} \mathrm{K}^{+}$exhibits significantly decreased reactivities in the presence of a complexing agent, 18crown-6-ether (18C6). The effect of added $18 \mathrm{C} 6$ on $k_{\text {obsd }}$ is illustrated in the inset of Figure 3, i.e., $k_{\text {obsd }}$ decreases sharply upon addition of $18 \mathrm{C} 6$ up to near $[18 \mathrm{C} 6] /\left[\mathrm{EtO}^{-} \mathrm{K}^{+}\right]=1$ and then remains nearly constant thereafter. This indicates clearly that $\mathrm{K}^{+}$ catalyzes the reactions of $\mathbf{5 c}$ and complexation of $\mathrm{K}^{+}$with $18 \mathrm{C} 6$ is completed at $[18 \mathrm{C} 6] /\left[\mathrm{EtO}^{-} \mathrm{K}^{+}\right]=1$.

Thus, plots of $k_{\mathrm{obsd}} /\left[\mathrm{EtO}^{-}\right]$vs. [ $\left.\mathrm{EtO}^{-}\right]$have been constructed to 


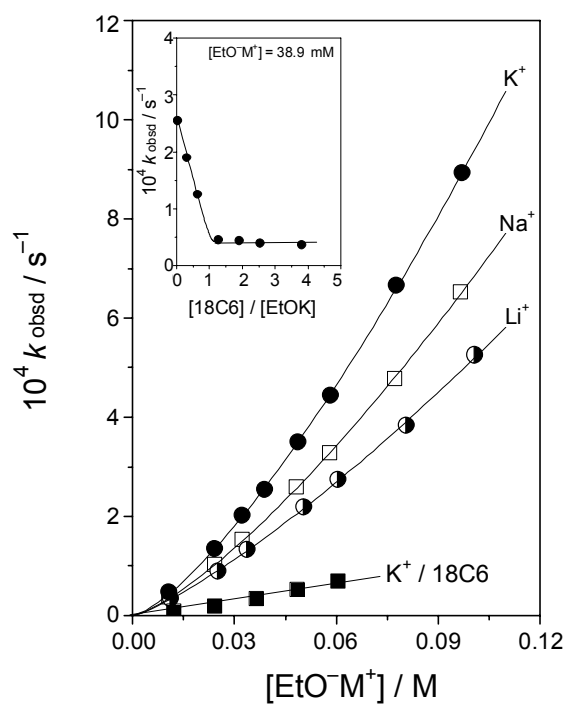

Figure 3. Plots of $k_{\text {obsd }} v s$. [EtO- $\mathrm{M}^{+}$] for reactions of 4-nitrophenyl 4hydroxybenzoate $(\mathbf{5 c})$ with $\mathrm{EtO} \mathrm{K}^{+}(\bullet), \mathrm{EtO} \mathrm{Na}^{+}(\square), \mathrm{EtO} \mathrm{Li}^{+}(\mathbf{\bullet})$, and $\mathrm{EtO} \mathrm{K}^{+}$in the presence of $18 \mathrm{C} 6\left(\mathbf{m},[18 \mathrm{C} 6] /\left[\mathrm{EtO} \mathrm{K}^{+}\right]=2\right)$ in anhydrous $\mathrm{EtOH}$ at $25.0 \pm 0.1^{\circ} \mathrm{C}$. The inset demonstrates the effect of added $18 \mathrm{C} 6$ on $k_{\text {obsd }}$ for the reactions of $\mathbf{5 c}$ with $\mathrm{EtO}^{-} \mathrm{K}^{+}$.

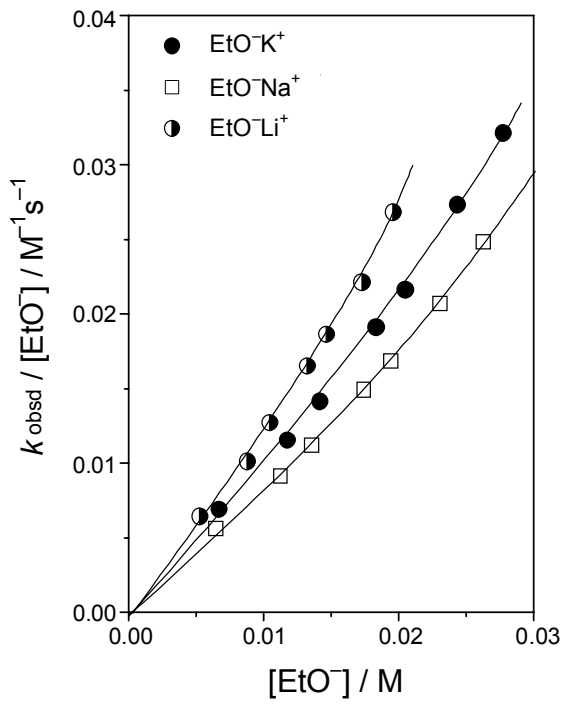

Figure 4. Plots illustrating dissection of $k_{\mathrm{obsd}}$ into rate constants $k_{\mathrm{EtO}^{-}}$ and $k_{\mathrm{EtO}^{-}} \mathrm{M}^{+}$for reactions of 4-nitrophenyl 4-hydroxybenzoate $(\mathbf{5 c})$ with $\mathrm{EtO}^{-} \mathrm{M}^{+}$in anhydrous $\mathrm{EtOH}$ at $25.0 \pm 0.1^{\circ} \mathrm{C}$.

calculate $k_{\mathrm{EtO}}$ and $k_{\mathrm{EtO}^{-} \mathrm{M}^{+}}$. As in the preceding section for the reactions of $\mathbf{5 a}$ and $\mathbf{5 b}$, one might expect the plots should be linear. However, as shown in Figure 4 , the plots of $k_{\text {obsd }} /[\mathrm{EtO}]$ $v s$. [EtO] curve upward, indicating that the simple ion-pair treatment applied to the reactions of $\mathbf{5 a}$ and $\mathbf{5 b}$ cannot be applicable to the reaction of $\mathbf{5 c}$.

One might suggest that reactions of $\mathbf{5 c}$ with $\mathrm{EtO}^{-} \mathrm{M}^{+}$proceed through a dissociative mechanism (e.g., E2 or E1 cb) as shown in Scheme 3. Such dissociative mechanism is not possible for the reactions of $\mathbf{5 a}$ and $\mathbf{5 b}$. Thus, one might suggest that the difference in reaction mechanisms would be responsible for the fact that the simple ion-pair treatment, which has been applied

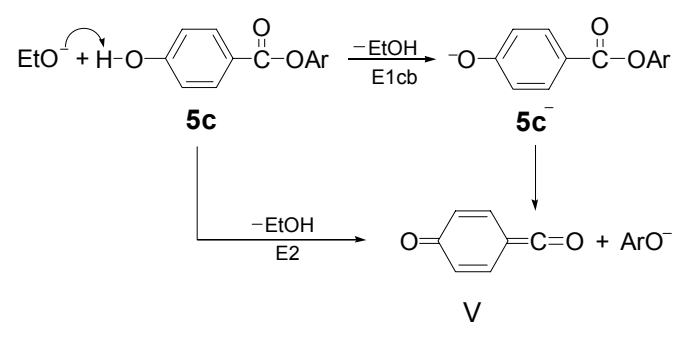

Scheme 3

to the reactions of $\mathbf{5 a}$ and $\mathbf{5 b}$, cannot be applicable to the reactions of $\mathbf{5 c}$.

Cevasco et al. have reported that alkaline hydrolysis of aryl 4-hydroxybenzoates proceeds mainly through an E1cb mechanism with a 4-oxoketene intermediate $\mathrm{V}$, when the $\mathrm{p} K_{\mathrm{a}}$ of the conjugate acid of the leaving group becomes lower than $6.5 .^{16}$ Since the $\mathrm{p} K_{\mathrm{a}}$ of 4-nitrophenol, the conjugate acid of the leaving group of $\mathbf{5 c}$, is 7.14, one might suggest that the reaction of $\mathbf{5 c}$ would not proceed through an E2 or E1cb mechanism. Furthermore, such dissociative mechanism cannot account for the $\mathrm{M}^{+}$ effect found for the reactions of $\mathbf{5 c}$. Thus, we propose that the curved plots shown in Figure 4 are not due to a dissociative mechanism but are caused by the nature of substrate $\mathbf{5 c}$ as discussed below.

It is assumed that substrate $\mathbf{5 c}$ is fully ionized to give an anionic form $\mathbf{5 c ^ { - }}$ in the kinetic condition (e.g., in strongly basic $\mathrm{EtO}^{-}$ $\mathrm{M}^{+}$solutions). Accordingly, the anionic substrate $5 \mathrm{c}^{-}$would interact with $\mathrm{M}^{+}$ions in the ground state (GS) as well as in the transition state (TS). The negative charge of $\mathbf{5 c}^{-}$in the GS would be localized either on the $\mathrm{O}$ atom of the phenoxy moiety or $\mathrm{C}=\mathrm{O}$ bond. Thus, pre-association of $\mathrm{M}^{+}$with $\mathbf{5 c}^{-}$would result in VI or VII, which could lower the activation energy by decreasing charge repulsion between the anionic reagents (i.e., $\mathrm{EtO}^{-}$ and $\mathbf{5 c}$ ). Furthermore, VI might increase electrophilicity of the reaction center by localizing the negative charge on the phenoxy oxygen. In contrast, VII could not increase the electrophilicity, since the $\mathrm{C}=\mathrm{O}$ bond is already polarized. Thus, $\mathrm{VI}$ is expected to be more reactive than VII.

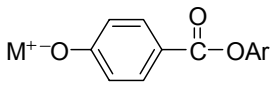

VI

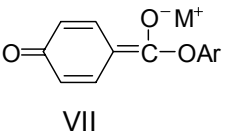

VII
One might suggest that two metal ions are involved in the reactions of $\mathbf{5 \mathbf { c } ^ { - }}$ as shown in Scheme 4, in which two "new" rate constants are introduced (i.e., $k^{\prime} \mathrm{EtO}^{-}$and $k^{\prime}{ }_{\mathrm{EtO}^{-} \mathrm{M}^{+}}$for attack of dissociate $\mathrm{EtO}^{-}$and ion-paired $\mathrm{EtO}^{-} \mathrm{M}^{+}$on a metal-complexed substrate VI, respectively).

Accordingly, the mechanism shown in Scheme 4 leads to the rate law in eq (4), which can be represented as eq (5), where the association constant, $K_{\mathrm{c}}=\left[\mathrm{M}^{+} \mathbf{5} \mathrm{c}^{-}\right] /\left[\mathrm{M}^{+}\right][\mathbf{5 c}]$.

$$
\begin{aligned}
\text { Rate }= & k_{\mathrm{EtO}^{-}}\left[\mathrm{EtO}^{-}\right]\left[\mathbf{5 c}^{-}\right]+k^{\prime}{ }_{\mathrm{EtO}}-\left[\mathrm{EtO}^{-}\right]\left[\mathrm{M}^{+} \mathbf{5} \mathbf{c}^{-}\right] \\
& +k_{\mathrm{EtO}^{-} \mathrm{M}^{+}}\left[\mathrm{EtO}^{-} \mathrm{M}^{+}\right]\left[\mathbf{5 c}^{-}\right] \\
& +k_{\mathrm{EtO}^{-} \mathrm{M}^{+}}\left[\mathrm{EtO}^{-} \mathrm{M}^{+}\right]\left[\mathrm{M}^{+} \mathbf{5} \mathbf{c}\right]
\end{aligned}
$$




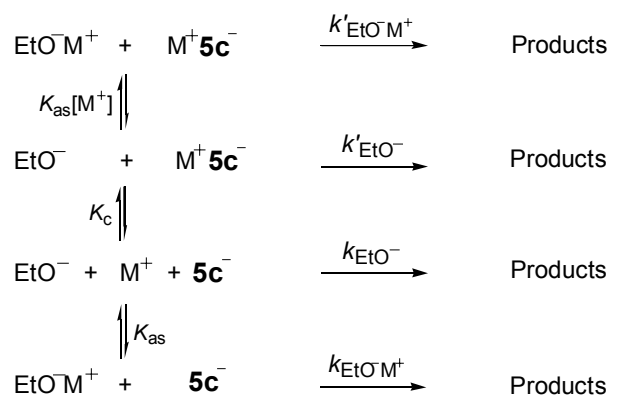

Scheme 4

Table 2. Summary of the Coefficients Determined from the Curve Fitting (Figure 5) for the Reactions of 4-nitrophenyl 4-hydroxybenzoate (5c) with $\mathrm{EtO}^{-} \mathrm{M}^{+}$in anhydrous $\mathrm{EtOH}$ at $25.0 \pm 0.1{ }^{\circ} \mathrm{C}^{a}{ }^{a} k_{\mathrm{EtO}^{-}}=1.30 \times 10^{-3}$ $\mathrm{M}^{-1} \mathrm{~s}^{-1}$.

\begin{tabular}{cccc}
\hline $\mathrm{EtO}^{-} \mathrm{M}^{+}$ & $\left(k^{\prime} \mathrm{EtO}^{-} K_{\mathrm{c}}+k_{\mathrm{EtO}^{-} \mathrm{M}^{+}} K_{\mathrm{as}}\right)$ & $\left(k^{\prime} \mathrm{EtO}^{-} \mathrm{M}^{+} K_{\mathrm{c}} K_{\mathrm{as}}\right)$ & $k_{\mathrm{EtO}^{\top} \mathrm{M}^{+}}^{\prime} K_{\mathrm{c}}$ \\
\hline $\mathrm{EtO} \mathrm{Li}^{+}$ & $0.808 \pm 0.052$ & $24.5 \pm 3.0$ & $0.116 \pm 0.014$ \\
$\mathrm{EtO} \mathrm{Na}^{+}$ & $0.540 \pm 0.016$ & $13.3 \pm 0.7$ & $0.130 \pm 0.007$ \\
$\mathrm{EtO}^{-} \mathrm{K}^{+}$ & $0.675 \pm 0.016$ & $15.7 \pm 0.7$ & $0.174 \pm 0.008$
\end{tabular}

${ }^{a} \mathrm{The} K_{\text {as }}$ values of $\mathrm{EtO}^{-} \mathrm{Li}^{+}, \mathrm{EtO}^{-\mathrm{Na}^{+}}$and $\mathrm{EtO}^{-} \mathrm{K}^{+}$used to calculate $k^{\prime} \mathrm{EtO}^{-\mathrm{M}^{+}} K_{\mathrm{c}}$ are 212,102 , and $90 \mathrm{M}^{-1}$ for this series. See text and reference 12 .

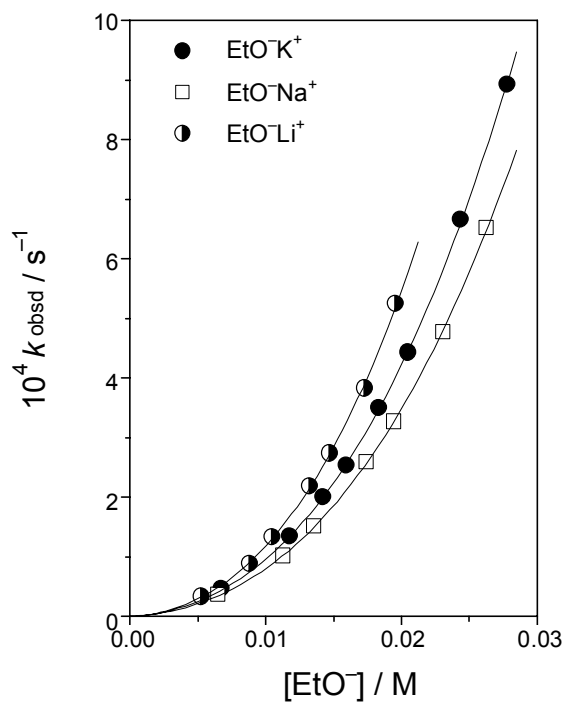

Figure 5. Plots of $k_{\mathrm{obsd}} v s$. [EtO ${ }^{-}$for reactions of 4-nitrophenyl 4hydroxybenzoate $(\mathbf{5 c})$ with $\mathrm{EtO}^{-} \mathrm{M}^{+}$in anhydrous $\mathrm{EtOH}$ at $25.0 \pm 0.1^{\circ} \mathrm{C}$. The curved lines were drawn from eq (5).

$$
\begin{aligned}
k_{\mathrm{obsd}}= & k_{\mathrm{EtO}^{-}}\left[\mathrm{EtO}^{-}\right]+\left(k^{\prime}{ }_{\mathrm{EtO}^{-}} K_{\mathrm{c}}+k_{\mathrm{EtO}^{-} \mathrm{M}^{+}} K_{\mathrm{as}}\right)\left[\mathrm{EtO}^{-}\right]^{2} \\
& +k^{\prime}{ }_{\mathrm{EtO}^{-} \mathrm{M}^{+}} K_{\mathrm{c}} K_{\mathrm{as}}\left[\mathrm{EtO}^{3}\right]^{3}
\end{aligned}
$$

The relationship given in eq (5) is more complex than in eq (3) due to the presence of the $[\mathrm{EtO}]^{3}$ term. However, it was possible to fit the experimental data to eq (5) using a spreadsheet program with $k_{\mathrm{EtO}^{-}}=1.30 \times 10^{-3} \mathrm{M}^{-1} \mathrm{~s}^{-1}$ as an input value, which was determined from the slope of the plot of $k_{\text {obsd }} v s$. [EtO $\mathrm{K}^{+}$] for the reaction of $5 \mathbf{c}$ with $\mathrm{EtO}^{-} \mathrm{K}^{+}$in the presence of $18 \mathrm{C} 6$ (e.g., $\left.[18 \mathrm{C} 6] /\left[\mathrm{EtO}^{-} \mathrm{K}^{+}\right]=2\right)$. The $k_{\mathrm{EtO}^{-}}$value determined in this way is reliable, since $\mathrm{K}^{+}$ion has been shown to be fully complexed by $18 \mathrm{C} 6$ when $[18 \mathrm{C} 6] /\left[\mathrm{EtO}^{+}\right]=1$ (see inset of Figure $3)$. The other unknown constants such as $\left(k^{\prime}{ }_{\mathrm{EtO}}^{-} K_{\mathrm{c}}+k_{\mathrm{EtO}^{-} \mathrm{M}^{+}} K_{\mathrm{as}}\right)$ and $k^{\prime} \mathrm{EtO}^{-} \mathrm{M}^{+} K_{\mathrm{c}} K_{\text {as }}$ were optimized iteratively until the best fit to the experimental data was observed. The results are summarized in Table 2 and illustrated in Figure 5. However, unfortunately, $k^{\prime}{ }_{\mathrm{EtO}}{ }^{-}$and $k^{\prime} \mathrm{EtO}^{-} \mathrm{M}^{+}$values could not be calculated, since $K_{\mathrm{c}}$ and $K_{\mathrm{M}}$ values are not available.

Figure 5 shows that the experimental data fit nicely to eq (5), which was derived from the mechanism involving two $\mathrm{M}^{+}$ions, indicating that the mechanism proposed in Scheme 4 is adequate to account for the kinetic result obtained for the reactions of $\mathbf{5 c}$ with $\mathrm{EtO}^{-} \mathrm{M}^{+}$. The fact that $\mathrm{M}^{+}$catalyzes the reaction of $\mathbf{5 c}$ indicates that $\mathrm{M}^{+}$ions stabilize TS more strongly than GS. Thus, one can suggest VIII as a plausible TS structure, where two metal ions are involved, i.e., the one on the phenoxy oxygen could decrease the charge repulsion between the anionic reagents $\left(\mathrm{EtO}^{-}\right.$and $\mathbf{5 c}$ ) while the other one on the carbonyl oxygen could increase the electrophilicity of the electrophilic center. Clearly, both metal ions in VIII could lower the activation energy.

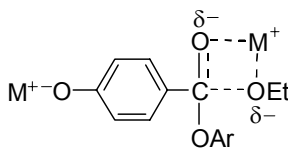

VIII

\section{Conclusions}

Our study has allowed us to conclude the following: (1) $\mathrm{M}^{+}$ ions catalyze the current reactions and the ion-paired $\mathrm{EtO}^{-} \mathrm{M}^{+}$ species are more reactive than the dissociated $\mathrm{EtO}^{-}$. (2) The second-order rate constants $k_{\mathrm{EtO}^{-}}$and $k_{\mathrm{EtO}^{-} \mathrm{M}^{+}}$have been determined from ion-pair treatment for the reactions of $\mathbf{5 a}$ and $\mathbf{5 b}$ but not for those of $\mathbf{5 c}$. (3) The reactions of $\mathbf{5} \mathbf{a}$ and $\mathbf{5 b}$ are catalyzed by one $\mathrm{M}^{+}$ion, which could increase the electrophilicity of the reaction center through coordination on the carbonyl oxygen. (4) Two $\mathrm{M}^{+}$ions are involved in the reactions of $\mathbf{5 c}$, i.e., the one associated with the phenoxy oxygen could decrease the charge repulsion between the anionic reagents (i.e., $\mathrm{EtO}^{-}$and $\mathbf{5 c}$ ) while the other one coordinated on the on the carbonyl oxygen could increase the electrophilicity of the reaction center. (5) Catalytic effect of $\mathrm{M}^{+}$ions increases as the size of $\mathrm{M}^{+}$increases and is more significant for the reactions of $\mathbf{5} \mathbf{c}$ than for those of $\mathbf{5 a}$ and 5 b.

\section{Experimental Section}

Materials. Compounds $\mathbf{5 a}$ and $\mathbf{5 b}$ were readily prepared from the reactions of the respective benzoyl chloride with 4-nitrophenol in the presence of triethylamine in anhydrous ether. Compound 5c was prepared from the reaction of 4-hydroxybenzoic acid and 4-nitrophenol in the presence of dicyclohexylcarbodiimide (DCC) and 4-dimethylaminopyridine (DMAP) in methylenechloride. The crude compounds 5a-c were purified by column chromatography. The solutions of $\mathrm{EtO}^{-} \mathrm{M}^{+}$were prepared by dissolving the respective alkali metal in anhydrous 
ethanol under $\mathrm{N}_{2}$ and stored in the refrigerator. The concentrations of $\mathrm{EtO}^{-} \mathrm{M}^{+}$were determined by titration with mono potassium phthalate. 18-Crown-6-ether was recrystallized from acetonitrile and dried under vacuum. The anhydrous ethanol used was further dried over magnesium and distilled under $\mathrm{N}_{2}$ just before reactions.

Kinetics. Kinetic study was performed using a Uv-vis spectrophotometer equipped with a constant-temperature circulating bath. The reactions were followed by monitoring the appearance of the leaving 4-nitrophenoxide at $400 \mathrm{~nm}$. Generally, reactions were followed for 9 - 10 half-lives and $k_{\text {obsd }}$ were calculated using the equation, $\ln \left(A_{\infty}-A_{t}\right)$ vs. $t$.

Product Analysis. 4-Nitrophenoxide was liberated quantitatively and identified as one of the reaction products by comparison of the Uv-vis spectra after completion of the reactions with those of the authentic samples under the reaction conditions.

Acknowledgments. This research was supported by Basic Science Research Program through the National Research Foundation of Korea (NRF) funded by the Ministry of Education, Science and Technology (2009-0075488).

Supplementary Materials. Supplementary Tables S1-S4 for kinetic conditions and results are available at the bkcs website (http://www.kcsnet.or.kr/bkcs).

\section{References}

1. Reviews: (a) Brown, R. S.; Neverov, A. A. Adv. Phys. Org. Chem. 2007, 42, 271-331. (b) Brown, R. S.; Neverov, A. A.; Tsang J. S. W.; Gibson, G. T. T.; Montoya-Pelaez, P. J. Can. J. Chem. 2004, 82, 1791-1805. (c) Williams, N. H.; Takasaki, B.; Wall, M.; Chin, J. Acc. Chem. Res. 1999, 32, 485-493. (d) Pregel, M. J.; Dunn, E. J.; Nagelkerke, R.; Thatcher, G. R. J.; Buncel, E. Chem. Soc. Rev. 1995, 24, 449-455.

2. (a) Fife, T. H.; Chauffe, L. Bioorg. Chem. 2000, 28, 357-373. (b) Fife, T. H.; Bembi, R. J. Am. Chem. Soc. 1993, 115, 11358-11363. (c) Fife, T. H.; Pujari, M. P. J. Am. Chem. Soc. 1990, 112, 55515557.

3. (a) Kim, H. M.; Jang, B.; Cheon, Y. E.; Suh, M. P.; Suh, J. J. Biol. Inorg. Chem. 2009, 14, 151-157. (b) Jang, B.; Suh, J. Bull. Korean Chem. Soc. 2008, 29, 202-204. (c) Jang, S. W.; Suh, J. Org. Lett. 2008, 10, 481-484. (d) Kim, M. G.; Kim, M. S.; Lee, S. D.; Suh, J. J. Biol. Inorg. Chem. 2006, 11, 867-875. (e) Suh, J.; Son, S. J.; Suh, M. P. Inorg. Chem. 1998, 37, 4872-4877. (f) Suh, J.; Kim, N.; Cho, H. S. Bioorg. Med. Chem. Lett. 1994, 4, 1889-1892.

4. (a) Edwards, D. R.; Liu, C. T.; Garrett, G. E.; Neverov, A. A.; Brown, R. S. J. Am. Chem. Soc. 2009, 131, 13738-13748. (b) Liu, C. T.; Melnychuk, S. A.; Liu, C.; Neverov, A. A.; Brown, R. S. Can. J. Chem. 2009, 87, 640-649. (c) Tsang, W. Y.; Edwards, D. R;
Melnychuk, S. A.; Liu, C. T.; Liu, C.; Neverov, A. A.; Willams, N. H.; Brown, R. S. J. Am. Chem. Soc. 2009, 131, 4159-4166. (d) Edwards, D. R.; Neverov, A. A.; Brown, R. S. J. Am. Chem. Soc. 2009, 131, 368-377. (e) Liu, C. T.; Neverov, A. A.; Brown, R. S. J. Am. Chem. Soc. 2008, 1301, 16711-16720. (f) Gibson, G. T. T.; Mohamed, M. F.; Neverov, A. A.; Brown, R. S. Inorg. Chem. 2006, 45, 7895-7902. (g) Gibson, G. T. T.; Neverov, A. A.; Teng, A. C.-T.; Brown, R. S. Can. J. Chem. 2005, 83, 1268-1276.

5. (a) Dunn, E. J.; Buncel, E. Can. J. Chem. 1989, 67, 1440-1448. (b) Buncel, E.; Dunn, E. J.; Bannard, R. B.; Purdon J. G. Chem. Commun. 1984, 162-163.

6. (a) Buncel, E.; Albright, K. G.; Onyido, I. Org. Biomol. Chem. 2005, 3, 1468-1475. (b) Buncel, E.; Albright, K. G.; Onyido, I. Org. Biomol. Chem. 2004, 2, 601-610. (c) Nagelkerke, R.; Thatcher, G. R. J.; Buncel, E. Org. Biomol. Chem. 2003, 1, 163-167.

7. Buncel, E.; Nagelkerke, R.; Thatcher, G. R. J. Can. J. Chem. 2003, 81, 53-63.

8. (a) Pregel, M. J.; Dunn, E. J.; Buncel, E. J. Am. Chem. Soc. 1991, 113, 3545-3550. (b) Pregel, M. J.; Buncel, E. J. Org. Chem. 1991, 56, 5583-5588. (c) Pregel, M. J.; Dunn, E. J.; Buncel, E. Can. J. Chem. 1990, 68, 1846-1858. (d) Buncel, E.; Pregel, M. J. J. Chem. Soc., Chem. Commun. 1989, 1566-1567.

9. (a) Um, I. H.; Shin, Y. H.; Lee, S. E.; Yang, K.; Buncel, E. J. Org. Chem. 2008, 73, 923-930. (b) Um, I. H.; Jeon, S. E.; Baek, M. H.; Park, H. R. Chem. Commun. 2003, 3016-3017.

10. (a) Um, I. H.; Lee, S. E.; Hong, Y. J.; Park, J. E. Bull. Korean Chem. Soc. 2008, 29, 117-121. (b) Um, I. H.; Hong, Y. J.; Lee, Y. J. Bull. Korean Chem. Soc. 1998, 19, 147-150. (c) Um, I. H.; Nahm, J. H.; Lee, Y. J.; Kwon, D. S. Bull. Korean Chem. Soc. 1996, 17, 840-845.

11. Pechanec, V.; Kocian, O.; Zavada, J. Collect. Czech. Chem. Commun. 1982, 47, 3405-3411.

12. Barthel, J.; Justice, J.-C.; Wachter, R. Z. Phys. Chem. 1973, 84 , 100-113.

13. Um, I. H.; Hong, Y. J.; Kwon, D. S. Tetrahedron 1997, 53, 50735082.

14. (a) Um, I. H.; Lee, J. Y.; Ko, S. H.; Bae, S. K. J. Org. Chem. 2006 , 71, 5800-5803. (b) Um, I. H.; Lee, J. Y.; Fujio, M.; Tsuno, Y. Org. Biomol. Chem. 2006, 4, 2979-2985. (c) Um, I. H.; Jeon, S. E.; Seok, J. A. Chem. Eur. J. 2006, 12, 1237-1243. (d) Um, I. H.; Kim, K. H.; Park, H. R.; Fujio, M.; Tsuno, Y. J. Org. Chem. 2004, 69, 39373942. (e) Um, I. H.; Han, H. J.; Ahn, J. A.; Kang, S.; Buncel, E. J. Org. Chem. 2002, 67, 8475-8480. (f) Um, I. H.; Min, J. S.; Ahn, J. A.; Hahn, H. J. J. Org. Chem. 2000, 65, 5659-5663.

15. (a) Um, I. H.; Kim, E. H.; Lee, J. Y. J. Org. Chem. 2009, 74, $1212-$ 1217. (b) Um, I. H.; Hwang, S. J.; Yoon, S.; Jeon, S. E.; Bae, S. K. J. Org. Chem. 2008, 73, 7671-7677. (c) Um, I. H.; Lee, J. Y.; Kim, H. T.; Bae, S. K. J. Org. Chem. 2004, 69, 2436-2441. (d) Um, I. H.; Chun, S. M.; Chae, O. M.; Fujio, M.; Tsuno, Y. J. Org. Chem. 2004, 69, 3166-3172. (e) Um, I. H.; Hong, J. Y.; Kim, J. J.; Chae, O. M.; Bae, S. K. J. Org. Chem. 2003, 68, 5180-5185.

16. (a) Cevasco, G.; Vigo, D.; Thea, S. Org. Lett. 1999, 1, 1165-1167. (b) Cevasco, G.; Guanti, G.; Hopkins, A. R.; Thea, S.; Williams, A. J. Org. Chem. 1985, 50, 479-484. (c) Thea, S.; Cevasco, G.; Guanti, G.; Kashefi-Naini, N.; Williams, A. J. Org. Chem. 1985, 50, 18671872. 